Article

\title{
Tantalum-Titanium Oxynitride Thin Films Deposited by DC Reactive Magnetron Co-Sputtering: Mechanical, Optical, and Electrical Characterization
}

\author{
Daniel Cristea $^{1}(\mathbb{D})$, Ioana-Laura Velicu ${ }^{2, *(\mathbb{D})}$, Luis Cunha ${ }^{3}\left(\mathbb{D}\right.$, Nuno Barradas ${ }^{4}$, Eduardo Alves ${ }^{5}$ \\ and Valentin Craciun ${ }^{6}$ (D)
}

Citation: Cristea, D.; Velicu, I.-L.; Cunha, L.; Barradas, N.; Alves, E.;

Craciun, V. Tantalum-Titanium Oxynitride Thin Films Deposited by DC Reactive Magnetron

Co-Sputtering: Mechanical, Optical, and Electrical Characterization. Coatings 2022, 12, 36. https:// doi.org/10.3390/coatings12010036

Academic Editor: Philipp Vladimirovich KiryukhantsevKorneev

Received: 30 November 2021 Accepted: 23 December 2021 Published: 28 December 2021

Publisher's Note: MDPI stays neutral with regard to jurisdictional claims in published maps and institutional affiliations.

Copyright: (C) 2021 by the authors. Licensee MDPI, Basel, Switzerland. This article is an open access article distributed under the terms and conditions of the Creative Commons Attribution (CC BY) license (https:// creativecommons.org/licenses/by/ $4.0 /)$
Materials Science Department, Transilvania University, 500036 Brasov, Romania; daniel.cristea@unitbv.ro Faculty of Physics, Alexandru Ioan Cuza University, 700506 Iasi, Romania

Physics Centre of Minho and Porto Universities, 4710-057 Braga, Portugal; lcunha@fisica.uminho.pt

4 Nuclear Science and Technology Centre, Technical Superior Institute, University of Lisbon, 2695-066 Bobadela LRS, Portugal; nunoni@ctn.tecnico.ulisboa.pt

5 Institute of Plasma and Nuclear Fusion, Technical Superior Institute, University of Lisbon, 2695-066 Bobadela LRS, Portugal; ealves@ctn.tecnico.ulisboa.pt

6 Laser Department, National Institute for Laser, Plasma, and Radiation Physics, 077125 Magurele, Romania; valentin.craciun@inflpr.ro

* Correspondence: laura.velicu@uaic.ro

\begin{abstract}
The possibility to tune the elemental composition and structure of binary Me oxynitridetype compounds $\left(\mathrm{Me}_{1} \mathrm{Me}_{2} \mathrm{ON}\right)$ could lead to attractive properties for several applications. For this work, tantalum-titanium oxynitride (TaTiON) thin films were deposited by DC reactive magnetron co-sputtering, with a $-50 \mathrm{~V}$ bias voltage applied to the substrate holder and a constant substrate temperature of $100{ }^{\circ} \mathrm{C}$. To increase or to decrease in a controlled manner, the Ti and Ta content in the co-sputtered films, the Ti and Ta target currents were varied between 0.00 and $1.00 \mathrm{~A}$, in $0.25 \mathrm{~A}$ steps, while keeping the sum of the currents applied to the two targets at $1.00 \mathrm{~A}$. The reactive gases flow, consisting of a nitrogen and oxygen gas mixture with a constant $\mathrm{N}_{2} / \mathrm{O}_{2}$ ratio $(85 \% / 15 \%)$, was also kept constant. The single-metal oxynitrides ( $\mathrm{TaON}$ and TiON) showed a low degree of crystallinity, while all the other co-sputtered films revealed themselves to be essentially amorphous. These two films also exhibited higher adhesion to the metallic substrate. The TaON film showed the highest hardness value $(14.8 \mathrm{GPa})$ and the TiON film a much lower one $(8.8 \mathrm{GPa})$, while the co-sputtered coatings exhibited intermediary values. One of the most interesting findings was the significant increase in the $\mathrm{O}$ content when the Ti concentration surpassed the Ta one. This significantly influenced the optical characteristic of the films, but also their electrical properties. The sheet resistivity of the co-sputtered films is strongly dependent on the $\mathrm{O} /(\mathrm{Ta}+\mathrm{Ti})$ atomic ratio.
\end{abstract}

Keywords: ternary oxynitride; co-sputtering; hardness; adhesion; wear

\section{Introduction}

Transition metal oxynitrides are a group of ceramic materials that are characterized by the possibility of changing the ratio between the nitrogen and oxygen content, and the one between the transition metal and the non-metallic elements $(\mathrm{Me} /(\mathrm{O}+\mathrm{N}))$, which allows for controlling a broad spectrum of properties suitable for many applications: optical properties, especially obtaining a wide range of colours; electrical properties, from conductive to insulating, variable mechanical properties, etc.

Hereinafter, a short overview on the tantalum and titanium-based oxides, nitrides, and oxynitrides ( $\mathrm{TaO}, \mathrm{TaN}, \mathrm{TaON}, \mathrm{TiO}, \mathrm{TiN}, \mathrm{TiON})$ will be presented, with emphasis on their actual and potential applications.

One of the most common variants of tantalum oxides is tantalum pentoxide $\left(\mathrm{Ta}_{2} \mathrm{O}_{5}\right)$. It is extensively studied due to its high dielectric constant, high refractive index and 
good thermal and chemical stability, properties which make it a strong candidate for microelectronics applications. Other applications of tantalum pentoxide include antireflection coatings deposited on the surface of solar cells, optical transmission paths (optical fibres), insulating material in devices requiring high permittivity [1], as well as in the manufacture of metal-oxide-semiconductor field effect transistors [2]. Tantalum pentoxide can also be used as protective coatings or components of storage capacitors in HDRAM (High-density random-access memory) units. Related to the example presented above, there are a few drawbacks, the most significant being related to the fact that tantalum pentoxide crystallizes at temperatures above $600{ }^{\circ} \mathrm{C}$, with negative effects on its performance [1] Due to its high chemical stability, tantalum pentoxide is also a promising biocompatible material, and it can be used as a catalytic material for wastewater treatment and for the decomposition of water to obtain hydrogen for energy purposes [3,4].

Transition metal nitrides are known for their remarkable properties which include high hardness, high temperature stability, chemical stability, etc. These nitrides can be used as wear-resistant coatings, protective coatings and structural elements in integrated circuits, among other applications. Tantalum nitride can be used as thin-layer resistors [5], diffusion barriers [6] or wear-resistant hard layers [7,8]. The properties of tantalum nitride thin films depend on their microstructure and composition. A search in the literature, regarding the reported tantalum nitride phases, resulted in an extensive list. Some examples are $\mathrm{TaN}_{0.05}$, $\mathrm{Ta}_{2} \mathrm{~N}, \mathrm{TaN}_{0.8-0.9}$, and $\mathrm{TaN}$ [9], $\varepsilon-\mathrm{TaN}, \theta-\mathrm{TaN}$ and $\delta-\mathrm{TaN}$ [10], $\mathrm{Ta}_{2} \mathrm{~N}, \mathrm{Ta}_{5} \mathrm{~N}_{6}$, and $\mathrm{Ta}_{3} \mathrm{~N}_{5}$ [11]. The electronic properties range from good conductors, like $\mathrm{Ta}_{2} \mathrm{~N}, \mathrm{TaN}$ or $\mathrm{Ta}_{5} \mathrm{~N}_{6}$ to more semiconductor phases, like $\mathrm{Ta}_{3} \mathrm{~N}_{5}$ [11].

Tantalum oxynitrides demonstrate having application potential, in general, in a much larger domain, in relation to the corresponding metallic nitrides and oxides [12-14]. In terms of electrical resistivity, it was found that this parameter varies in a very large domain. As a thin film, produced by magnetron sputtering, its electrical resistivity may vary from $5.29 \times 10^{-4} \Omega \mathrm{cm}$ (for a flow of $2.5 \mathrm{sccm}$ of reactive gas - $15 \% \mathrm{O}_{2}+85 \% \mathrm{~N}_{2}$ - and a grounded substrate holder), up to $1.93 \times 10^{6} \Omega \mathrm{cm}$ (for a flow of $30 \mathrm{sccm}$ of reactive gas mixture and a substrate polarization voltage of $-100 \mathrm{~V}$ ) [12]. Hardness values for tantalum oxynitride coatings, varying from $\sim 7 \mathrm{GPa}$ up to $\sim 22 \mathrm{GPa}$, depending on their composition and structure, have been previously reported [14].

Titanium oxide is one of the most studied titanium-based materials. Titanium oxide films were proposed for photocatalytic, electronic, optical, and optoelectronic applications [15-17]. Moreover, other applications are reported for $\mathrm{TiO}_{2}$, namely: corrosion resistant coatings, anti-bacterial coatings, self-cleaning surfaces, etc. [18].

Titanium nitride has also been extensively studied. It is a versatile ceramic material, which exhibits good wear and corrosion resistant properties, being widely applied on cutting tools. Moreover, titanium nitride has biocompatible properties as well as a combination of high ductility and hardness, leading to its use in the medical implants field [19].

The properties of TiON thin films depend on the $\mathrm{O} / \mathrm{N}$ and $\mathrm{Ti} /(\mathrm{O}+\mathrm{N})$ ratios. TiON films can be used in many fields of applications: medical devices, selective solar absorbers, dielectric layers, resistive layer in memory devices, thin film resistors, and as a photocatalyst [20]. Moreover, TiON films can be also used as decorative coatings due to the colour variation when the $\mathrm{O} / \mathrm{N}$ ratio is changed [21].

Since oxynitride coatings based on transition metals $(\mathrm{MeON})$ can benefit from the properties of the respective oxides or nitrides of the particular metal, or can be characterized by entirely new properties, the possibility to tune the elemental composition and the structure of binary Me oxynitride-type compounds, containing two transitional metals $\left(\mathrm{Me}_{1} \mathrm{Me}_{2} \mathrm{ON}-\right.$ type), could further lead to attractive properties for several applications. Hereinafter, results concerning some mechanical properties (hardness, elastic modulus, adhesion to the substrate, wear behaviour), optical properties (colour coordinates and reflectance), and electrical properties (sheet resistance) of co-sputtered TaTiON coatings will be correlated to their deposition parameters, and to their chemical composition and structure. 


\section{Materials and Methods}

Films belonging to the TaTiON system were deposited onto several types of substrates by DC reactive co-magnetron sputtering. The selected substrates, needed for various analysis techniques, were glass slides, silicon wafers, and AISI 316L steel disks $(20 \mathrm{~mm}$ in diameter, $1.5 \mathrm{~mm}$ in thickness) polished to a mirror-like finish. Before being inserted in the chamber, all the substrates were cleaned with ethanol, to remove impurities from the surface. Prior to the deposition process, the chamber was evacuated to a base pressure lower than $1 \times 10^{-5} \mathrm{~Pa}$. The substrate holder was positioned at $70 \mathrm{~mm}$ from the high purity targets (Ta and $\mathrm{Ti} 99.6 \%$ ) with dimensions $200 \mathrm{~mm} \times 100 \mathrm{~mm} \times 6 \mathrm{~mm}$. A suitable rotation speed of the substrate holder was employed, to avoid the deposition of multilayer structures. Before each deposition, the substrates were plasma etched, using a pulsed direct current of $0.6 \mathrm{~A}$, during $500 \mathrm{~s}$, in an argon atmosphere, with a partial pressure around $0.3 \mathrm{~Pa}$. The gas atmosphere during the deposition process was composed of argon as working gas and a reactive mixture of nitrogen + oxygen $\left(15 \% \mathrm{O}_{2}+85 \% \mathrm{~N}_{2}\right)$. The argon flow $(70 \mathrm{sccm})$ was kept constant during all depositions, as well as the $\mathrm{N}_{2}+\mathrm{O}_{2}$ gas mixture flow $(10 \mathrm{sccm})$. The films were deposited with a $-50 \mathrm{~V}$ bias voltage applied to the substrate holder. The substrate holder was heated by the Joule effect, thermostatically controlled to maintain the temperature at $100{ }^{\circ} \mathrm{C}$ for all depositions. The temperature was measured using a thermocouple. The homogeneity of the substrate temperature was guaranteed by connecting the heater significantly before the beginning of the deposition (never less than $3 \mathrm{~h}$ ) and by the rotation of the substrate holder during the deposition. The main variable parameter was the applied target current on each target. To increase or to decrease, in a controlled manner, the Ti and Ta content in the deposited films, the Ti and Ta targets currents were varied between 0.00 and $1.00 \mathrm{~A}$, in $0.25 \mathrm{~A}$ steps, but keeping the sum of the currents in both targets always equal to $1.00 \mathrm{~A}$. The equivalent total current density in each deposition was $50 \mathrm{~A} / \mathrm{m}^{2}$. These current configurations led to five different deposition sessions, each one with the duration of $3600 \mathrm{~s}$. Detailed deposition parameters can be found in Table 1.

Table 1. Values of the experimental parameters used to deposit by reactive magnetron co-sputtering films belonging to the TaTiON system $\left(t_{\mathrm{f}}=\right.$ thickness of the films).

\begin{tabular}{|c|c|c|c|c|c|c|c|c|}
\hline \multirow[t]{2}{*}{ Sample Code } & \multicolumn{2}{|c|}{$\begin{array}{c}\text { Targets Current } \\
\text { (A) }\end{array}$} & \multicolumn{2}{|c|}{$\begin{array}{l}\text { Targets Voltage } \\
\text { (V) }\end{array}$} & \multirow{2}{*}{$\begin{array}{c}\left(\mathrm{N}_{2}+\mathrm{O}_{2}\right) \\
\text { Flow } \\
(\mathrm{sccm})\end{array}$} & \multirow{2}{*}{$\begin{array}{l}\text { Ar Flow } \\
\text { (sccm) }\end{array}$} & \multirow{2}{*}{$\begin{array}{l}\text { Bias } \\
(\mathrm{V})\end{array}$} & \multirow[t]{2}{*}{$t_{f}(n m)$} \\
\hline & Ta & $\mathrm{Ti}$ & Ta & $\mathrm{Ti}$ & & & & \\
\hline Ta1-Ti0-ON & 1 & 0 & 391 & - & 10 & 70 & -50 & $934 \pm 85$ \\
\hline Ta0.75-Ti0.25-ON & 0.75 & 0.25 & 424 & 360 & 10 & 70 & -50 & $1006 \pm 96$ \\
\hline Ta0.5-Ti0.5-ON & 0.50 & 0.50 & 421 & 383 & 10 & 70 & -50 & $677 \pm 73$ \\
\hline Ta0.25-Ti0.75-ON & 0.25 & 0.75 & 425 & 397 & 10 & 70 & -50 & $417 \pm 63$ \\
\hline Ta0-Ti1-ON & 0 & 1 & - & 436 & 10 & 70 & -50 & $220 \pm 44$ \\
\hline
\end{tabular}

The chemical composition of the coatings was assessed by Rutherford backscattering Spectrometry (RBS). The measurements were made at the CTN/IST Van de Graaff accelerator in the small chamber, where three detectors are installed: standard at $140^{\circ}$, and two pin-diode detectors located symmetrical each other, both at $165^{\circ}$ (detector 3 on same side as standard detector 2). Spectra were collected for $2.3 \mathrm{MeV}^{4} \mathrm{He}^{+}$, under normal incidence. The RBS data were analysed with the IBA DataFurnace NDF v9.6 h [22]. Double scattering was calculated with the algorithms given elsewhere [23], while pileup was calculated with the algorithms given in [24]. Several of the samples showed spectral features which are characteristic to the presence of surface roughness, in some cases eventually with the formation of islands or other forms of surface non-uniformity. Consequently, the simulations were done by introducing a thin Ta layer with very large thickness standard deviation, between the film and the substrate. 
The structure of the films was analysed by grazing incidence and symmetrical Xray diffraction (GIXRD and XRD) investigations, performed on the films deposited on $\mathrm{Si}$ substrates with an Empyrean instrument (Panalytical, Almelo, Netherlands) set to work in a parallel beam geometry with $\mathrm{CuK}_{\alpha}$ radiation $(\lambda=1.540598 \AA)$, in the range of $2 \theta=30-100^{\circ}$.

Instrumented indentation measurements were performed on the films, to obtain the indentation hardness and the indentation elastic modulus, using a CSM Instruments / Anton Paar $\mathrm{NHT}^{2}$ nanoindenter (Corcelles-Cormondrèche, Switzerland), equipped with a Berkovich geometry diamond pyramidal tip (tip radius $=100 \mathrm{~nm}$ ), with the following protocol: $30 \mathrm{~s}$ loading to the desired load, $10 \mathrm{~s}$ pause (dwell time, to minimize the creep effect), $30 \mathrm{~s}$ unloading. The maximum applied load per each sample was chosen as a function of the coating thickness, to avoid the influence of the substrate on the final results. At least 20 indentations were performed on each sample. The coating thickness was measured in several locations by ball cratering, using a Calotest machine from CSM Instruments, equipped with a $30 \mathrm{~mm}$ steel ball and diamond slurry as the abrasive entity.

The adhesion of the coatings to the substrate was quantified by scratch tests, using a CSM Instruments / Anton Paar Microscratch Tester (Corcelles-Cormondrèche, Switzerland), equipped with a diamond Rockwell geometry tip (radius $=100 \mu \mathrm{m}$ ). On each sample, at least 5 tracks were performed, with the following protocol: progressive load from $0.03 \mathrm{~N}$ to $10.00 \mathrm{~N}$, loading rate $5.00 \mathrm{~N} / \mathrm{min}$, and scratch length of $2 \mathrm{~mm}$. The results of interest are the load responsible for the occurrence of the first cracks in the coating $(L c 1)$, the load necessary for the initial delamination $(L c 2)$, and the load needed for the removal of more than $50 \%$ of the coating (Lc3).

The wear behaviour was assessed on a rotational tribometer from CSM Instruments / Anton Paar (Corcelles-Cormondrèche, Switzerland), against $6 \mathrm{~mm}$ diameter $\mathrm{Al}_{2} \mathrm{O}_{3}$ balls. At least 3 wear tracks were carried out on each sample, with the following protocol: applied load of $1 \mathrm{~N}$, linear speed of $20 \mathrm{~cm} / \mathrm{s}$, stop condition $200 \mathrm{~m}$. Before each test, the samples and the friction couples were cleaned with ethanol and blow dried with compressed air.

The optical reflectance and the colour coordinates in the CIE L*a*b* space were recorded with a 3nh YS4510 portable spectrophotometer (wavelength 400-700 nm), in at least 3 regions of each sample, on the films deposited on glass slides, with a D65 standard illuminant source, a measurement aperture of $\phi 4 \mathrm{~mm}$, and a $10^{\circ}$ observation angle.

The sheet resistance was measured with an Ossila 4-point probe meter with a $1.27 \mathrm{~mm}$ spacing between the measuring probes, on the samples deposited on glass slides, using a linear fit for the voltage-current curves.

\section{Results and Discussion}

\subsection{Chemical Composition and Structural Development}

Figure 1 presents the thickness of the deposited films as a function of the $\mathrm{Ti}$ and Ta targets' applied currents. The trend coincides to that of the deposition rate, since the deposition period was set to $3600 \mathrm{~s}$ for each batch.

The thickness of the films decreases significantly from $\sim 900 \mathrm{~nm}$, for the sample without titanium (Ta1-Ti0-ON), down to $200 \mathrm{~nm}$, for the sample without tantalum (Ta0-Ti1-ON). It seems that a slight increase in the deposition rate happens from $I_{\mathrm{Ti}}=0.00 \mathrm{~A}\left(I_{\mathrm{Ta}}=1.00 \mathrm{~A}\right)$ to $I_{\mathrm{Ti}}=0.25 \mathrm{~A}\left(I_{\mathrm{Ta}}=0.75 \mathrm{~A}\right)$, but, for titanium target currents above $0.25 \mathrm{~A}$ (and tantalum currents below $0.75 \mathrm{~A}$ ), the co-sputtered coatings follow a decreasing linear trend of the thickness. The sputtering yield of these two elements is rather similar, which translates to relatively similar sputtering rates for the pure elements, the one for Ta being $85 \AA$ s, while the deposition rate for $\mathrm{Ti}$ is $80 \AA$ /s [25]. 


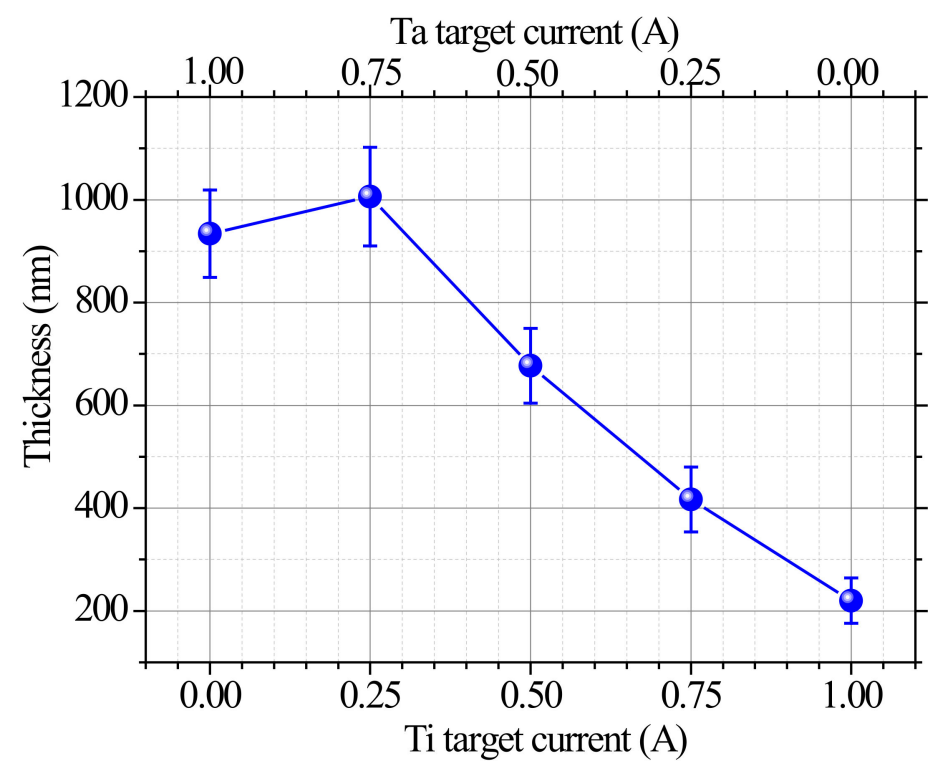

Figure 1. Coating thickness as a function of the Ti and Ta target applied currents.

The justification for the observed behaviour should be sought elsewhere. The sputtered atoms ejected into the gas phase are not in a pure thermodynamic equilibrium. In any case, the standard enthalpies of formation of the compounds, which might form during the deposition process, may help to explain the trend of the thickness (Figure 1) and the chemical composition (Figure 2). The values found in literature are: $\Delta H_{f}^{0}(\mathrm{TaN})=-251 \mathrm{~kJ} \cdot \mathrm{mol}^{-1}$, $\Delta H_{f}^{0}\left(\mathrm{TaO}_{2}\right)=-201 \mathrm{~kJ} \cdot \mathrm{mol}^{-1}, \Delta H_{f}^{0}\left(\mathrm{Ta}_{2} \mathrm{O}_{5}\right)=-2046 \mathrm{~kJ} \cdot \mathrm{mol}^{-1}, \Delta H_{f}^{0}(\mathrm{TiN})=-265.8 \mathrm{~kJ} \cdot \mathrm{mol}^{-1}$, $\Delta H_{f}^{0}(\mathrm{TiO})=-519.7 \mathrm{~kJ} \cdot \mathrm{mol}^{-1}, \Delta H_{f}^{0}\left(\mathrm{TiO}_{2}\right)=-944 \mathrm{~kJ} \cdot \mathrm{mol}^{-1}, \Delta H_{f}^{0}\left(\mathrm{Ti}_{2} \mathrm{O}_{3}\right)=-1520.9 \mathrm{~kJ} \cdot \mathrm{mol}^{-1}$, $\Delta H_{f}^{0}\left(\mathrm{Ti}_{3} \mathrm{O}_{5}\right)=-2459.4 \mathrm{~kJ} \cdot \mathrm{mol}^{-1}$ [26]. Based on these values, it would seem that, for similar stoichiometry compounds (e.g., $\mathrm{TaN}$ vs. $\mathrm{TiN}, \mathrm{TaO}_{2} \mathrm{vs}$. $\mathrm{TiO}_{2}$, etc.), the ones based on titanium are more favoured to be formed. The higher reactivity of Ti towards $\mathrm{N}$, and particularly towards $\mathrm{O}$, when compared to the affinity of Ta to the same elements, is reflected in Figure 2. When the current of the Ti target increases, the non-metal/metal ratios tend to increase, particularly the $\mathrm{O} / \mathrm{Ti}$ when $\mathrm{I}(\mathrm{Ti})>0.5 \mathrm{~A}$ (Figure $2 \mathrm{~b}$ ). Consequently, when the amount of Ti atoms sputtered from the target is increased, due to the higher applied current, the probability of formation of compounds (especially oxides) is higher. However, this phenomenon could lead to a higher degree of target poisoning, since the compounds are not only formed on the substrate surface, but on other surfaces of the deposition chamber (including the target) as well. Generally, the sputtering rate of compounds is significantly lower than that of the elemental targets. Since the target would be working in poisoned mode, fewer elemental atoms are released through sputtering, which could explain the lower deposition rate. Another aspect that may contribute to explaining the higher deposition rate observed for Ta richer films is related to the higher chemical bond length of Ta compounds compared to analogous $\mathrm{Ti}$ compounds (e.g., $\mathrm{TaN}$ vs. $\mathrm{TiN}, \mathrm{TaO}_{2}$ vs. $\mathrm{TiO}_{2}$, etc.). 


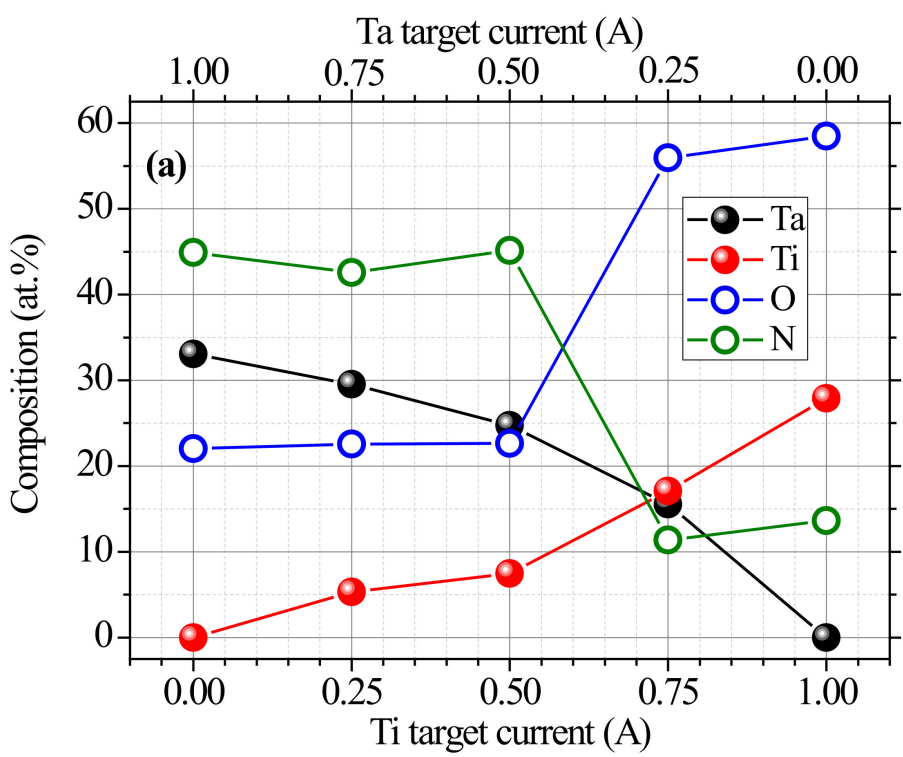

(a)

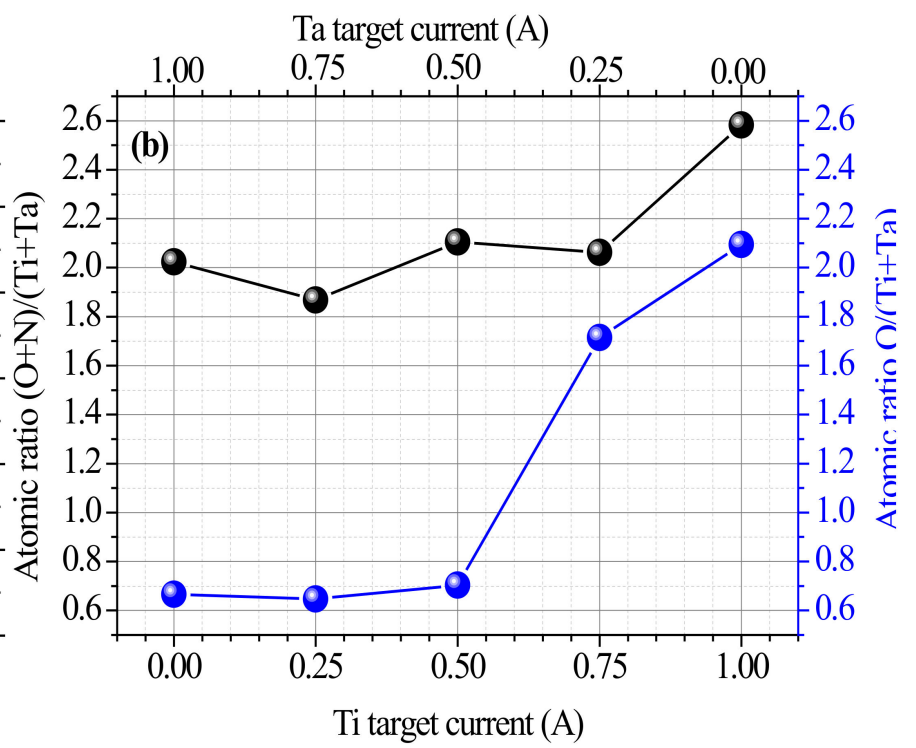

(b)

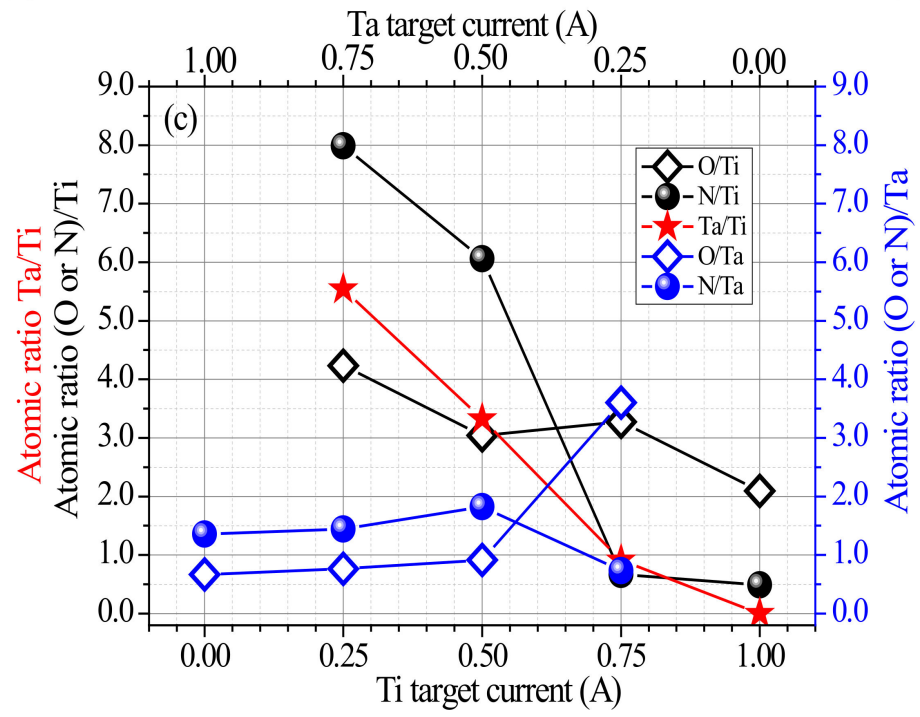

(c)

Figure 2. Chemical composition (a) and atomic ratios (b) and (c), as a function of Ti and Ta target applied currents.

Figure $3 a, b$ presents grazing incidence XRD patterns of the deposited oxynitride films. According to these results, due to the presence of characteristic diffraction peaks, the single metal element oxynitrides (Ta1-Ti0-ON and Ta0-Ti1-ON, Figure 3a) exhibit a certain degree of crystallinity. On the other hand, all the other co-sputtered samples (TaTiON, Figure $3 b$ ) showed an amorphous structure, regardless of the deposition parameters. 


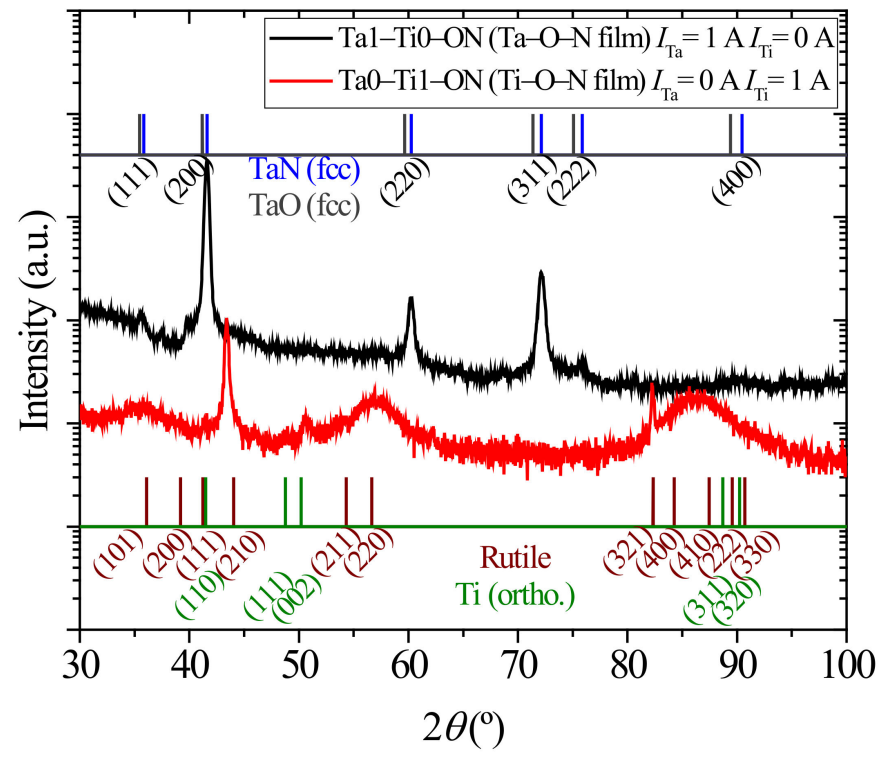

(a)

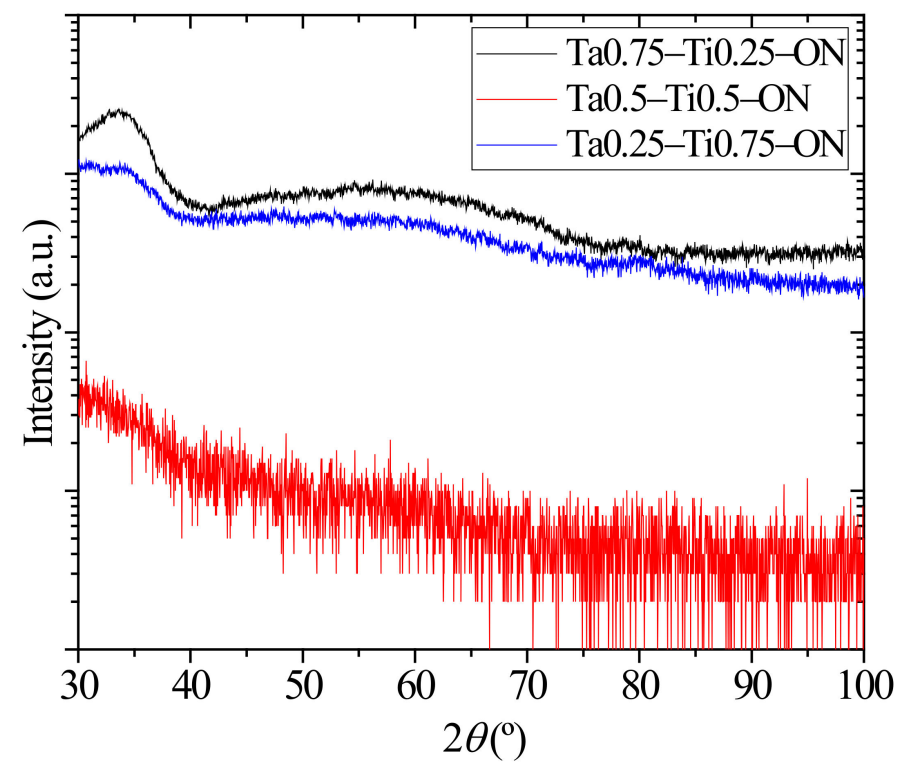

(b)

Figure 3. Grazing incidence XRD patterns of the single-sputtered coatings (a) and co-sputtered coatings $(\mathbf{b})$.

It seems that the competition occurring between the metallic elements, to react with the gases and to form compounds, leads to a hindering of the crystal formation and growth. It cannot be overlooked that the relatively high atomic radius difference between $\mathrm{Ti}$ and Ta does not contribute to the formation of perfect crystals, particularly in the case of substitution of $\mathrm{Ti}$ by $\mathrm{Ta}$ or $\mathrm{Ta}$ by $\mathrm{Ti}$, in the crystal lattices. The influence of the chemical composition can also be observed in relation to the phase attribution of the crystalline phases, depicted in Figure 3a. The formation of nitride crystallites was favoured during the deposition of the Ta1-Ti0-ON sample (TaON film), which can be correlated to the higher nitrogen content in the working atmosphere. In fact, when comparing the composition ratios of this sample (Figure $2 \mathrm{c}$ ), the $\mathrm{N} /$ Ta ratio $(\sim 1.4)$ is approximately double that of the $\mathrm{O} / \mathrm{Ta}$ ratio $(\sim 0.7)$. The XRD pattern of the TaON film exhibits significantly better-defined peaks, when compared with the TiON diffraction pattern, and reveals a polycrystalline structure. The diffraction peaks can be assigned to the face-centred cubic (fcc) phase of TaN (ICDD card 04-019-2403), probably doped with some oxygen. These diffraction peak positions are very close to those of the fcc phase of TaO (ICDD card 03-065-6750). Although the formation of $\mathrm{Ta}_{2} \mathrm{O}_{5}$ is thermodynamically favoured compared to the formation of TaN (see enthalpy of formation values), the kinetic mode prevails due to significantly higher $\mathrm{N}_{2}$ partial pressure when compared to $\mathrm{O}_{2}$.

Conversely, the diffraction peaks and bands corresponding to the Ta0-Ti1-ON sample (TiON film) coincide with the location of either metallic orthorhombic phase of Ti (ICDD card 00-055-0345), but more probably, based on the chemical composition of the sample, to the rutile phase of $\mathrm{TiO}_{2}$ (ICDD card 00-021-1276). One exception can be observed in the case of the diffraction peak located at $2 \theta=\sim 43.5^{\circ}$, where a peak of the $\mathrm{TiN}_{0.6} \mathrm{O}_{0.4}$ structure could be assigned (ICDD card 00-049-1325). In the case of the TiON film, the O/Ti ratio (2.1) is almost stoichiometric to $\mathrm{TiO}_{2}$, and it is significantly higher than the N/Ti ratio (0.5) (Figure 2c). Consequently, the formation of oxides is favoured over that of nitrides, although the $\mathrm{O}_{2} / \mathrm{N}_{2}$ ratio in the working atmosphere is less than 0.2. It seems that, in this case, the thermodynamic mode is predominant, particularly when compared to the phenomena observed for the TaON film. One can observe from the thermodynamic data that the difference between the enthalpy of formation values of the Ti oxides compared to the Ti nitrides is higher relatively to the analogous Ta oxides and nitrides. This fact has 
an impact on the composition (Figure 2a) and on the structural evolution (Figure 3a) of the films.

Furthermore, the samples obtained with intermediary current values (Ta0.75-Ti0.25$\mathrm{ON}$ and Ta0.25-Ti0.75-ON) exhibit a broad band in the $2 \theta=\sim 30^{\circ}-40^{\circ}$ region, which could signify the formation of poorly developed crystallites in an amorphous matrix. Going into more detail, for the co-sputtered film richer in $\mathrm{Ta}(\mathrm{Ta} / \mathrm{Ti}=5.5)$, the kinetic mode seems to dominate, inferred from the following: $\mathrm{N} /(\mathrm{Ta}$ or $\mathrm{Ti})>\mathrm{O} /(\mathrm{Ta}$ or $\mathrm{Ti})$. For the film richer in $\mathrm{Ti}$ $(\mathrm{Ta} / \mathrm{Ti}=0.9)$, the thermodynamic mode seems to prevail, since $\mathrm{O} /(\mathrm{Ta}$ or $\mathrm{Ti})>\mathrm{N} /(\mathrm{Ta}$ or $\mathrm{Ti})$. In a certain way, these results confirm the sputtering modes discussed above for the single metal oxynitride films.

The sample deposited with 0.5 A applied to each metallic target is entirely amorphous.

\subsection{Mechanical Properties}

The variation of both indentation hardness and elastic modulus, as a function of the applied current on each target, is shown in Figure 4. One can observe that these parameters vary in a rather large domain, from $\sim 7 \mathrm{GPa}$ up to $\sim 15 \mathrm{GPa}$ for the hardness, and from $\sim 70 \mathrm{GPa}$ up to $\sim 220 \mathrm{GPa}$ for the indentation elastic modulus. The observed trend is probably related to the higher $\mathrm{O}$ content promoted by the increase of the current on the Ti target current. The deviation observed in the case of Ta0-Ti1-ON sample (TiON film), especially in the case of hardness, can be a consequence of the significantly lower penetration depth of the indenter $(\sim 20 \mathrm{~nm})$, due to the lower thickness of the coating ( 200 nm). In situations like these, the combination of two factors may be responsible for the observed behaviour: the roughness and the indentation size effect (ISE), where the reduction of the load on the indenter and the indent size lead to an increase in the hardness as the load on the indenter decreases [27]. Using these two material characteristics ( $\mathrm{H}$ and E), the $H / E$ and $H^{3} / E^{2}$ ratios can be obtained, useful for predicting the behaviour of a material.

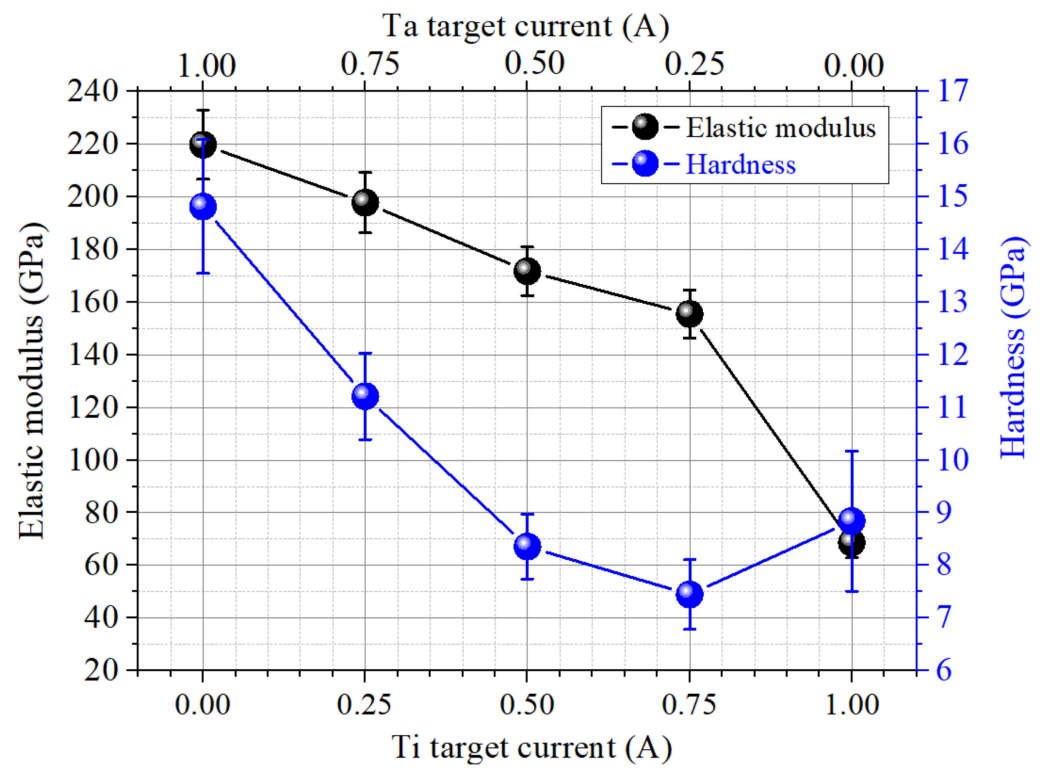

Figure 4. The variation of the indentation hardness and elastic modulus as a function of Ti and Ta target applied currents.

The variation of the $H / E$ and $H^{3} / E^{2}$ ratios as function of the deposition conditions is presented in Figure 5. The $H / E$ ratio, called elastic strain to failure, can be used to predict the resistance against wear of a material. Higher values for this ratio generally signify a better wear and failure resistance. Coatings with high hardness and rather low values of the indentation elastic modulus should exhibit improved facture toughness. Materials with high $H / E$ ratio have a small plasticity index, meaning that their deformation under load is more likely to be elastic than plastic. The consensus regarding this $H / E$ ratio is that, if it is 
larger than 0.1 , the material is resistant to cracking [28]. The $H^{3} / E^{2}$ ratio is used to assess the resistance to plastic deformation, highlighting the material's elasticity.

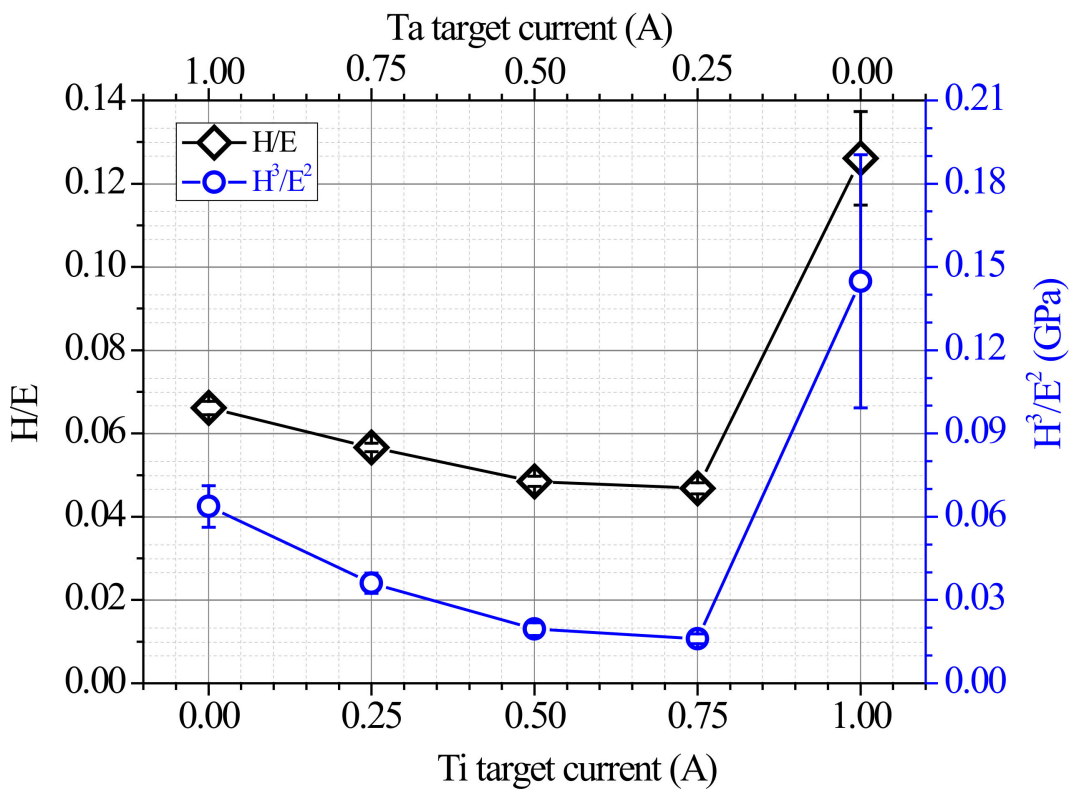

Figure 5. The variation of the $H / E$ and $H^{3} / E^{2}$ ratios $(H / E$-elastic strain to failure ratio, $H^{3} / E^{2}$-indicator of a material's resistance against plastic deformation) as a function of $\mathrm{Ti}$ and Ta target currents.

The critical loads obtained after the scratch tests, which give an indication on the adhesion/cohesion of the substrate/coating system, exhibiting relatively different trends, compared to the observed trends of the variation of $H$ and/or $E$ (Figure 6).

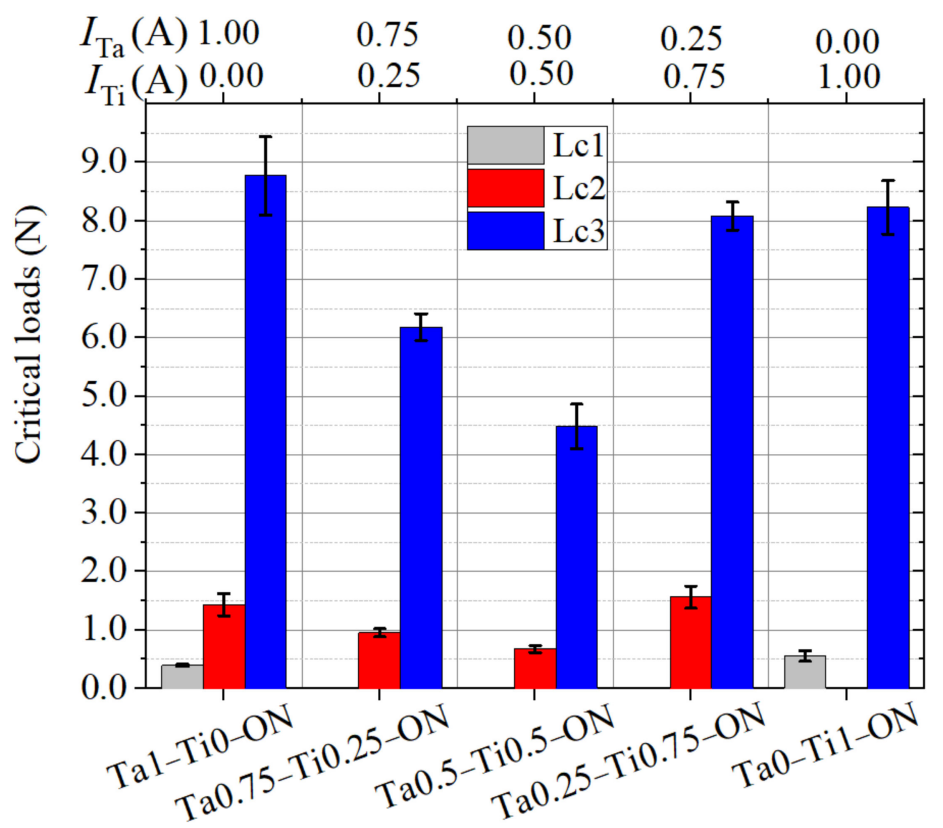

Figure 6. The variation of the scratch test adhesion critical loads: Lc1-first cracks; Lc2-first delamination; Lc3-total film removal.

It is worth mentioning that not all critical loads were observed on each sample. The amorphous samples did not exhibit the formation of any cracks for the selected interval of loads applied on the indenter, most probably due to their amorphous character and 
relatively low $H / E$ ratio values. Once the current applied on the Ta target is gradually decreased, both the load which causes the first delamination $(L c 1)$ and the one necessary for film removal $(L c 3)$ decrease. However, the samples with the highest oxygen content (Ta0-Ti1-ON) and the lowest nitrogen content (Ta0.25-Ti0.75-ON), both produced with $I(\mathrm{Ti}) \geq 0.75 \mathrm{~A}$ and $I(\mathrm{Ta}) \leq 0.25 \mathrm{~A}$, delaminate entirely due to increasingly higher loads.

Comparing the common critical load observed in all the substrate/film systems (Lc3) with the composition (Figure 7), a decrease of the critical load is observed when $I_{\text {Ta }}$ decreases ( $I_{\mathrm{Ti}}$ increases) until the targets are under the same current $(0.50 \mathrm{~A})$. This is probably due to the decrease of the Ta content, although the $\mathrm{N}$ content is more or less constant. As it was discussed previously, comparing the two metallic elements' affinity to the reactive species, tantalum atoms showed higher affinity to nitrogen than titanium atoms, forming tantalum nitride crystals (eventually with some $\mathrm{O}$ doping). The richest film in crystalline tantalum nitride (Ta1-Ti0-ON) is the hardest and the most adherent, and the continuous decrease of the Ta content does not contribute to the formation of this metal nitride and apparently the hardness and the adhesion are both decreasing, as a consequence. However, when $I_{\mathrm{Ti}}>0.50 \mathrm{~A}$, a significant increase of $\mathrm{O}$ content (and strong decrease of $\mathrm{N}$ content) was observed, and this fact seems to strongly contribute to an adhesion increase, although the hardness continues to decrease. This may be related with the relatively high ductility of these films, as the micrographs presented in Figure 8 show.

Based on the micrographs from Figure 8, the coatings seem to become more and more ductile as the oxygen content is increased (inferred from the aspect of the first delaminations $-L c 2$ ). The difference between the crystalline samples is most evident if one observes the shape and direction of the cracks in the coating $(L c 1)$, where sample Ta1-Ti0-ON exhibits tensile cracking, while sample Ta0-Ti1-ON exhibits conformal cracking. Moreover, sample Ta0-Ti1-ON was the only configuration that did not exhibit the occurrence of intermediary delaminations, a phenomenon which might be related to the fact that this sample is the only one which exhibits a $H / E$ ratio larger than 0.1 .

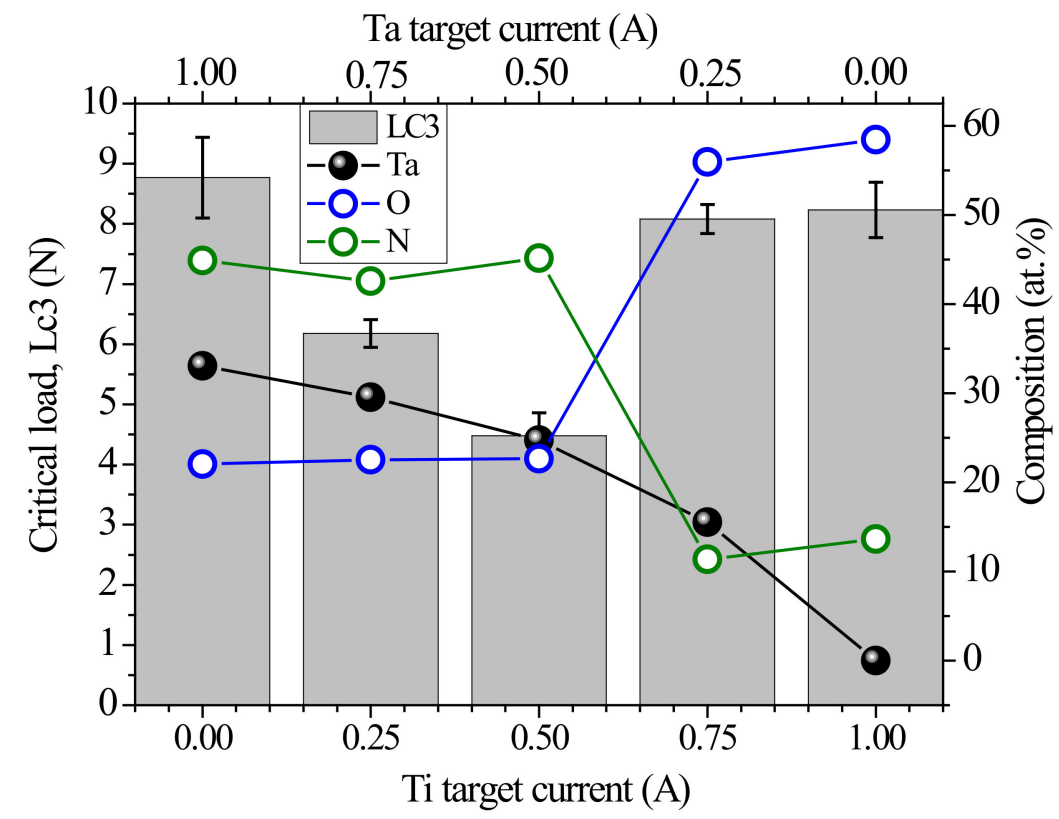

Figure 7. Correlation between critical load $L c 3$ and the composition and deposition parameters. 


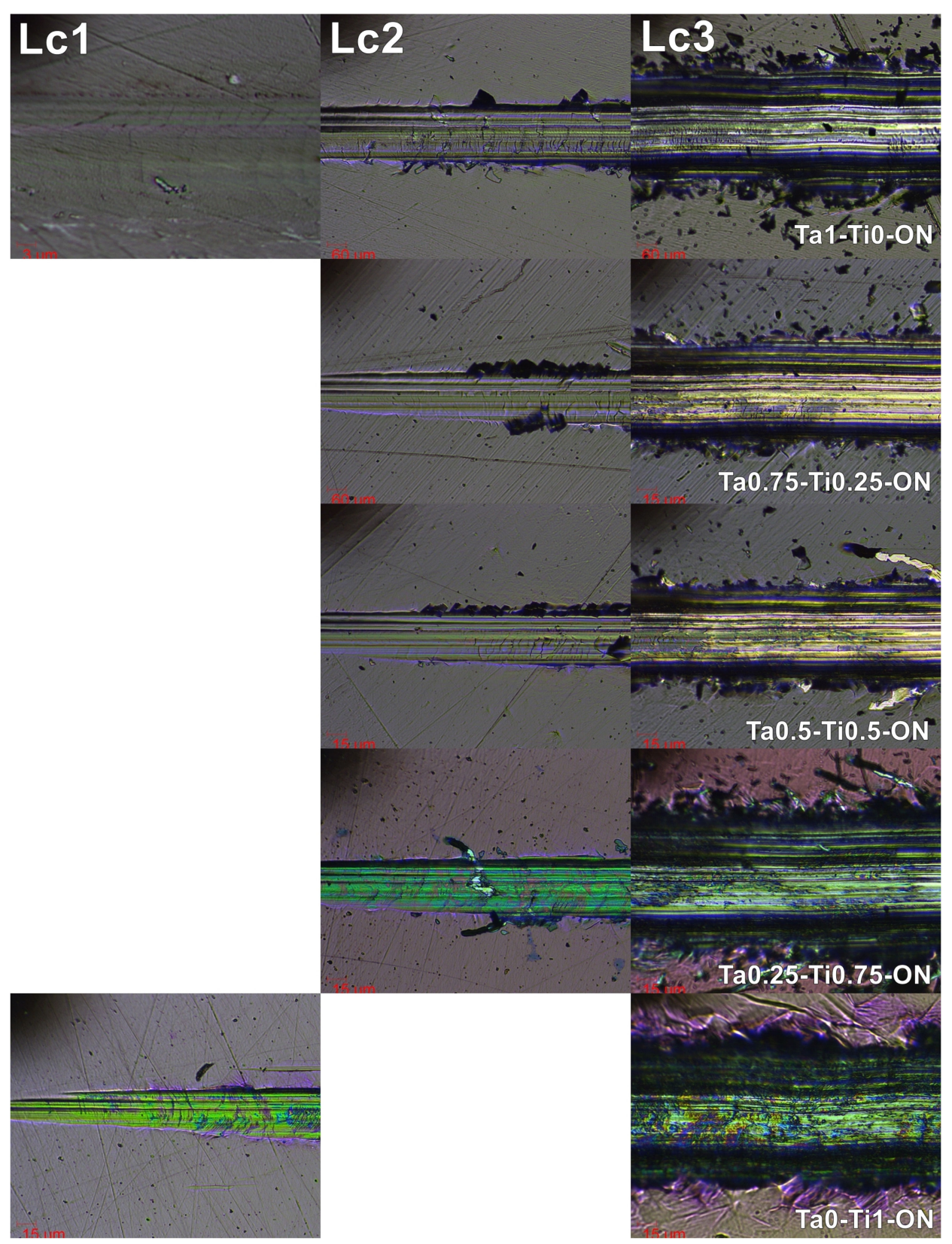

Figure 8. Representative micrographs of coating failure: $L c 1$-first cracks; $L c 2$-first delamination; Lc3-total film removal.

The wear behaviour was assessed on a rotational tribometer, against $\mathrm{Al}_{2} \mathrm{O}_{3}$ balls. From the variation of the friction coefficient as a function of distance, shown in Figure 9, the following observation can be made: all samples, with the exception of the bare substrate, exhibit a low friction regime, from up to $\sim 30 \mathrm{~m}$ for sample Ta1-Ti0-ON, down to $\sim 10 \mathrm{~m}$ for sample Ta0.5-Ti0.5-ON, followed by a high friction regime, which would signify that the substrate was breached by the $\mathrm{Al}_{2} \mathrm{O}_{3}$ ball. The better wear behaviour of sample Ta1Ti0-ON could be linked to its higher hardness. Interestingly, even if sample Ta0-Ti1-ON has the lowest thickness, it behaves adequately during wear tests, exhibiting a low friction regime for a larger duration relative to the other samples. 


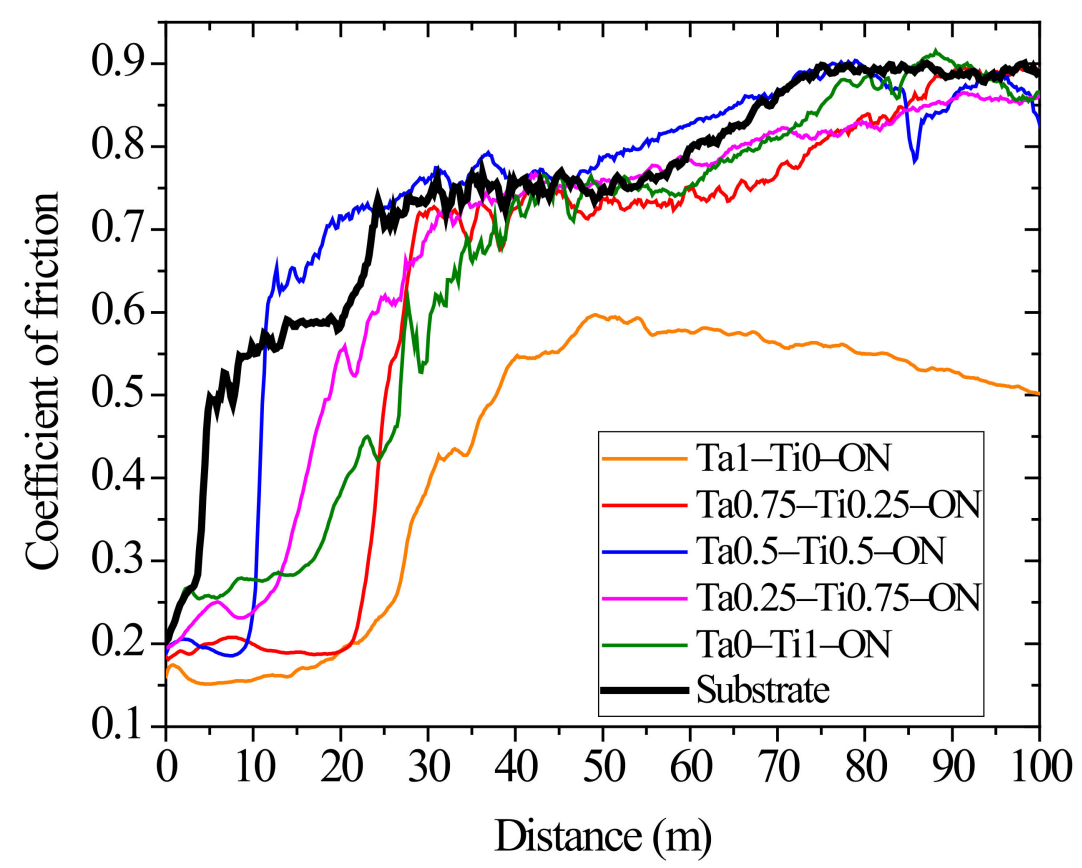

Figure 9. The variation of the friction coefficient as a function of distance.

\subsection{Colour Coordinates and Reflectance}

The perceived colour of the coatings deposited on steel substrates is shown in Figure 10. One can observe that two films with highest Ta-content (Ta1-Ti0-ON and Ta0.75-Ti0.25$\mathrm{ON}$ ) are dark-grey, while the ones with increasing $\mathrm{Ti}$ and $\mathrm{O}$ content exhibit typical interference coloration.

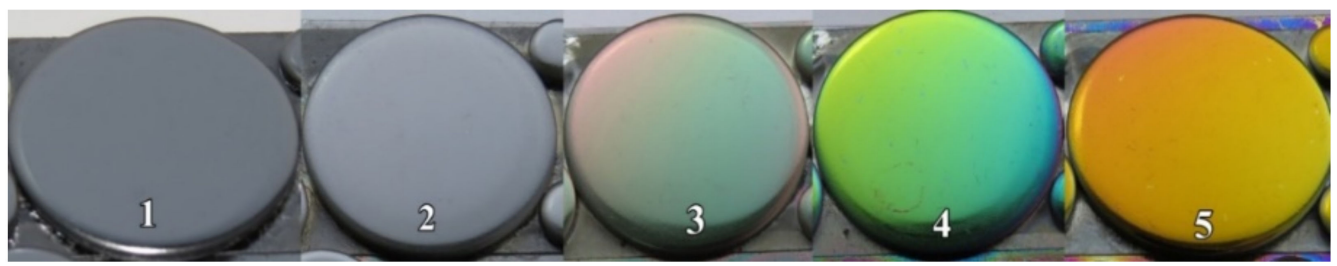

Figure 10. The perceived colour of the TaTiON coatings: $1-\mathrm{Ta} 1-\mathrm{Ti} 0-\mathrm{ON} ; 2-\mathrm{Ta} 0.75-\mathrm{Ti} 0.25-\mathrm{ON}$; 3-Ta0.5-Ti0.5-ON; 4-Ta0.25-Ti0.75-ON; 5-Ta0-Ti1-ON.

Since the perceived colour of a material depends on the illuminant, a proper comparison was made using the CIE $\mathrm{L}^{*} \mathrm{a}^{*} \mathrm{~b}^{*}$ colour coordinates system. The variation of the $\mathrm{L}^{*}$, $a^{*}$, and $b^{*}$ coordinates from the CIE L*a* $b^{*}$ colour space, as a function of the deposition parameters, is shown in Figure 11. The colour parameters of the two films produced with highest Ta target current (Ta1-Ti0-ON and Ta0.75-Ti0.25-ON) are significantly different from the remaining three films (shadowed region of Figure 11). The variation of the colour parameters between these two samples is relatively small, as expected from the perceived colour of Figure 10 . The lightness component $\left(\mathrm{L}^{*}\right)$ is close to 0 , coherently with the dark grey perceived colour. With regard to the chromatic components ( $a^{*}$ and $b^{*}$ ), both exhibit low chroma ( $a^{*}$ and $b^{*}$ very close to 0 ) and both suffer a slight shift to lower values: $a^{*}$ decreases from $0.13 \pm 0.22$ to $-0.39 \pm 0.19$, for sample Ta1-Ti0-ON (TaON film), and $b^{*}$ from $0.05 \pm 0.83$ to $-2.12 \pm 0.48$, for sample Ta0.75-Ti0.25-ON. 


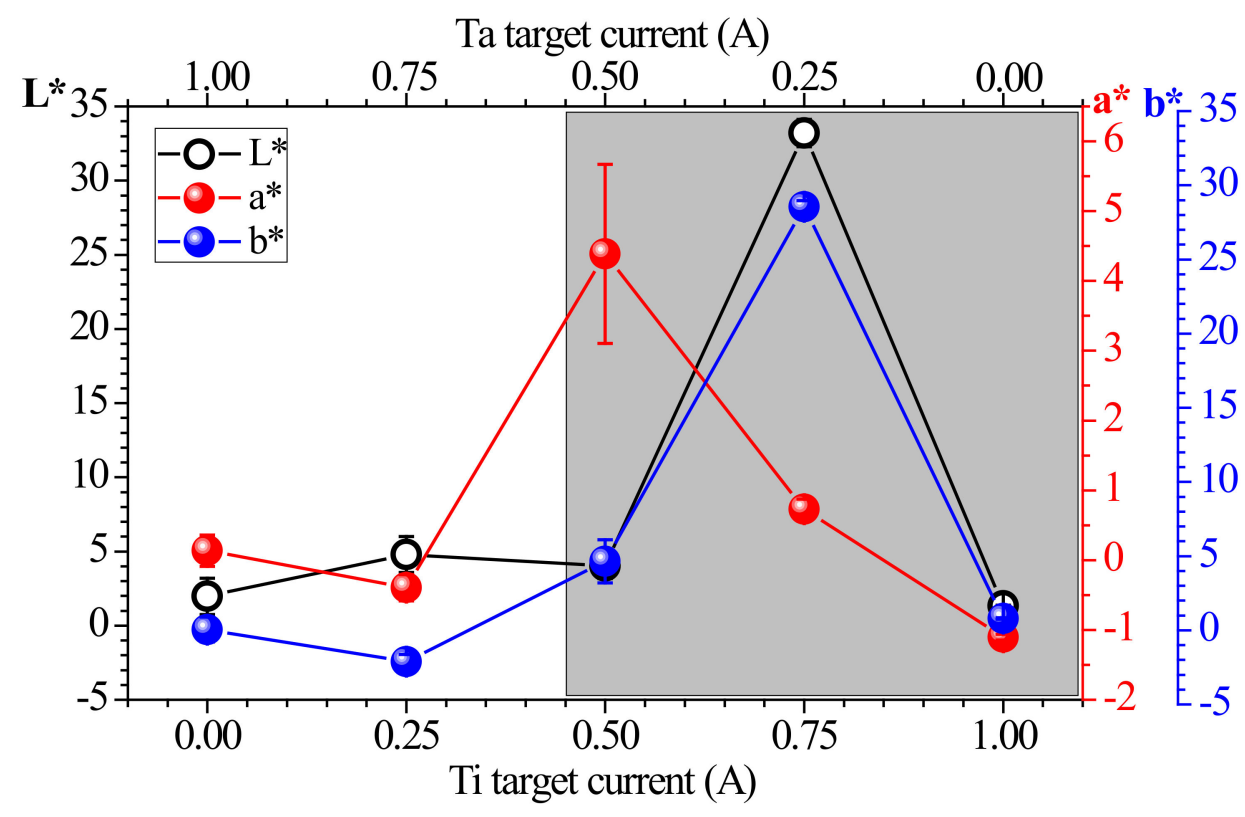

Figure 11. The variation of the colour coordinates in the CIE $\mathrm{L}^{*} \mathrm{a}^{*} \mathrm{~b}^{*}$ colour space.

The remaining three films exhibit large differences among them. It must be mentioned that these changes are not related only with the interaction with visible radiation with the film surface. The relatively high $\mathrm{O}$ content promotes the formation of oxides, which are generally transparent to visible light, as it is the case of $\mathrm{TiO}_{2}$. Because of this transparency, the colour parameters are resultant not only from the intrinsic colour of the film but also from what it is below the surface, substrate included. These observations can be confirmed by the diffuse reflectance spectra of the samples (Figure 12a,b).

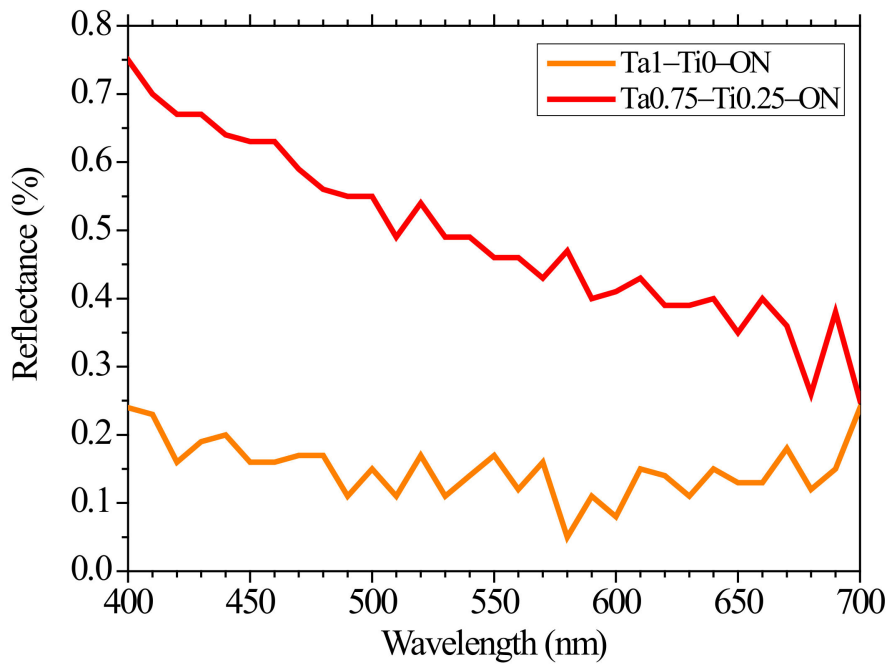

(a)

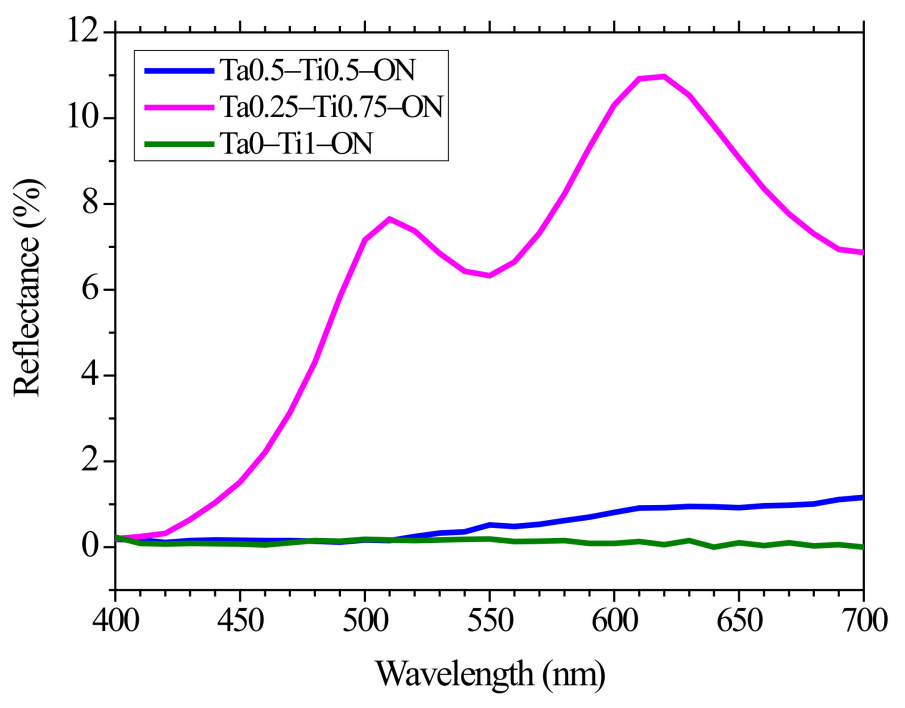

(b)

Figure 12. The variation of the reflectance as a function of the wavelength of the incident radiation: (a) Ta1-Ti0-ON and Ta0.75-Ti0.25-ON; (b) Ta0.50-Ti0.50-ON, Ta0.25-Ti0.75-ON and Ta0-Ti1-ON.

The reflectance spectra of Ta1-Ti0-ON and Ta0.75-Ti0.25-ON samples (Figure 12a) are low (dark films). The reflectance of the Ta0.25-Ti0.75-ON film is typical of a transparent material, exhibiting interference fringes coherent with its thickness (Table 1). The Ta0-Ti1ON sample (TiON film) seems to be too thin to exhibit the interference fringes, and the film produced with the same current applied to both targets (Ta050-Ti0.50-ON) is probably in 
the limit of being transparent to the visible radiation, although some waviness is detected when $\lambda>520 \mathrm{~nm}$.

\subsection{Sheet Resistance}

The values of the sheet resistance and of the $\mathrm{O} /$ metal ratio of the films produced in co-sputtering mode are depicted in Figure 13. As expected, a significant increase of the resistivity is observed when the $\mathrm{O}$ content of the samples increases. It would be difficult to find a better correlation between the sheet resistance and the atomic ratio $\mathrm{O} /(\mathrm{Ta}+\mathrm{Ti})$ as the one expressed in the figure.

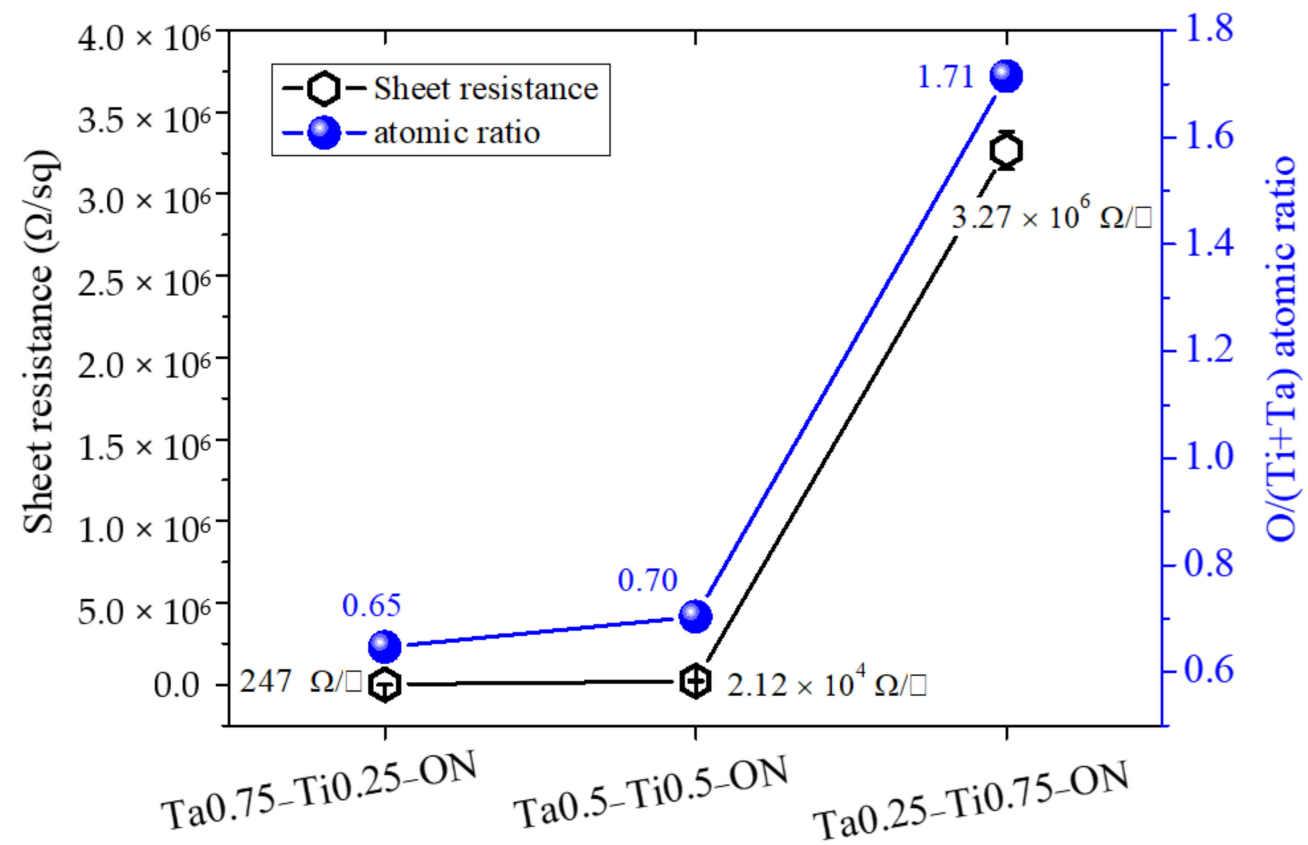

Figure 13. Sheet resistance measured by the 4-point probe method for the co-sputtered TaTiON coatings and correlation between sheet resistance and the $\mathrm{O} /(\mathrm{Ta}+\mathrm{Ti})$ atomic ratio.

\section{Conclusions}

Co-sputtered tantalum-titanium oxynitride (TaTiON) thin films were deposited systematically by reactive magnetron sputtering. A titanium oxynitride (TiON) and a tantalum oxynitride $(\mathrm{TaON})$ film were deposited in the same conditions of the co-sputtered films. Only these two single metal oxynitride films revealed some degree of crystallinity, higher for the $\mathrm{TaON}$ than the one exhibited by the TiON film. It was observed that the deposition rate is linked to the Ti content, the higher the Ti content, the lower deposition rate of the produced films. The deposition rate decreased from $2.8 \AA / \mathrm{s}$, for the film with the lowest Ti content, to $0.6 \AA / \mathrm{s}$ for the film with the highest Ti content. The single metal oxynitride films also exhibited the highest critical load values (total film removal), both higher than $8 \mathrm{~N}$. The TaON coating exhibited the highest hardest of all coatings (14.8 GPa), while the hardness of the TiON film was significantly lower $(8.8 \mathrm{GPa})$. The co-sputtered coatings have intermediary properties, in terms of mechanical behaviour (hardness, adhesion critical loads). A significant increase of the $\mathrm{O}$ content occurred for the films where the Ti concentration was larger than the one of Ta. Consequently, the optical characteristic of the films changed significantly: the films with highest $\mathrm{O}$ content became transparent to visible radiation, due to the formation of oxides, particularly titanium dioxide. The sheet resistance of the co-sputtered films revealed to be strongly dependent on the $\mathrm{O} /(\mathrm{Ta}+\mathrm{Ti})$ atomic ratio, varying in a rather large domain, from $247 \pm 0.07 \Omega$ /sq for the Ta0.75-Ti0.25-ON sample, up to $3.26 \pm 0.11 \times 10^{6} \Omega /$ sq for the Ta0.25-Ti0.75-ON sample. 


\begin{abstract}
Author Contributions: Conceptualization, D.C. and L.C.; methodology, D.C.; formal analysis, D.C., N.B., E.A. and V.C.; resources, D.C. and L.C.; data curation, D.C., I.-L.V. and L.C.; writing-original draft preparation, D.C. and L.C.; writing-review and editing, L.C. and I.-L.V.; project administration, D.C. and L.C.; funding acquisition, D.C. and L.C. All authors have read and agreed to the published version of the manuscript.
\end{abstract}

Funding: This research was funded by a grant of the Romanian Ministry of Education and Research, CNCS-UEFISCDI, project number PN-III-P1-1.1-TE-2019-1209, within PNCDI III. This work was also supported by the Portuguese Foundation for Science and Technology (FCT) in the framework of the Strategic Funding UIDB/04650/2020. V.C. acknowledges the Romanian Ministry of Research, NUCLEU Program LAPLAS VI (contract No. 16N/2019) and ELI-RO_2020_12.

Institutional Review Board Statement: Not applicable.

Informed Consent Statement: Not applicable.

Data Availability Statement: Not applicable.

Conflicts of Interest: The authors declare no conflict of interest.

Disclaimer: N.P. Barradas: Any views or opinions reflected here are those expressed by the author.

\title{
References
}

1. Jagadeesh Chandra, S.V.; Uthanna, S.; Mohan Rao, G. Effect of substrate temperature on the structural, optical and electrical properties of DC magnetron sputtered tantalum oxide films. Appl. Surf. Sci. 2008, 254, 1953-1960. [CrossRef]

2. Wei, A.X.; Ge, Z.X.; Zhao, X.H.; Liu, J.; Zhao, Y. Electrical and optical properties of tantalum oxide thin films prepared by reactive magnetron sputtering. J. Alloys Compd. 2011, 509, 9758-9763. [CrossRef]

3. Yang, W.M.; Liu, Y.W.; Zhang, Q.; Leng, Y.X.; Zhou, H.F.; Yang, P.; Chen, J.Y.; Huang, N. Biomedical response of tantalum oxide films deposited by DC reactive unbalanced magnetron sputtering. Surf. Coat. Technol. 2007, 201, 8062-8065. [CrossRef]

4. Jagadeesh Kumar, K.; Ravi Chandra Raju, N.; Subrahmanyam, A. Properties of pulsed reactive DC magnetron sputtered tantalum oxide $\left(\mathrm{Ta}_{2} \mathrm{O}_{5}\right)$ thin films for photocatalysis. Surf. Coat. Technol. 2011, 205, S261-S264. [CrossRef]

5. Sun, X.; Kolawa, E.; Chen, J.-S.; Reid, J.S.; Nicolet, M.A. Properties of reactively sputter-deposited Ta-N thin films. Thin Solid Films 1993, 236, 347-351. [CrossRef]

6. Kim, S.K.; Cha, B.C. Deposition of tantalum nitride thin films by D.C. magnetron sputtering. Thin Solid Films 2005, $475,202-207$. [CrossRef]

7. Aryasomayajula, A.; Valleti, K.; Aryasomayajula, S.; Bhat, D.G. Pulsed DC magnetron sputtered tantalum nitride hard coatings for tribological applications. Surf. Coat. Technol. 2006, 201, 4401-4405. [CrossRef]

8. Westergard, R.; Bromark, M.; Larsson, M.; Hedenqvist, P.; Hogmark, S. Mechanical and tribological characterization of DC magnetron sputtered tantalum nitride thin films. Surf. Coat. Technol. 1997, 97, 779-784. [CrossRef]

9. Swisher, J.H.; Read, M.H. Thermodynamic properties and electrical conductivity of $\mathrm{Ta}_{3} \mathrm{~N}_{5}$ and TaON. Metall. Trans. 1972, 3, 489-494. [CrossRef]

10. Liu, L.; Huang, K.; Hou, J.; Zhu, H. Structure refinement for tantalum nitrides nanocrystals with various morphologies. Mater. Res. Bull. 2012, 47, 1630-1635. [CrossRef]

11. Stampfl, C.; Freeman, A.J. Stable and metastable structures of the multiphase tantalum nitride system. Phys. Rev. B 2005, 71, 024111. [CrossRef]

12. Cristea, D.; Crisan, A.; Cretu, N.; Borges, J.; Lopes, C.; Cunha, L.; Ion, V.; Dinescu, M.; Barradas, N.P.; Alves, E.; et al. Structure dependent resistivity and dielectric characteristics of tantalum oxynitride thin films produced by magnetron sputtering. Appl. Surf. Sci. 2015, 354, 298-305. [CrossRef]

13. Cristea, D.; Crisan, A.; Munteanu, D.; Apreutesei, M.; Costa, M.F.; Cunha, L. Tantalum oxynitride thin films: Mechanical properties and wear behavior dependence on growth conditions. Surf. Coat. Technol. 2014, 258, 587-596. [CrossRef]

14. Cristea, D.; Cunha, L.; Gabor, C.; Ghiuta, I.; Croitoru, C.; Marin, A.; Velicu, L.; Besleaga, A.; Vasile, B. Tantalum Oxynitride Thin Films: Assessment of the Photocatalytic Efficiency and Antimicrobial Capacity. Nanomaterials 2019, 9, 476. [CrossRef]

15. Lou, B.S.; Chen, W.T.; Diyatmika, W.; Lu, J.H.; Chang, C.T.; Chen, P.W.; Lee, J.W. Effect of target poisoning ratios on the fabrication of titanium oxide coatings using superimposed high power impulse and medium frequency magnetron sputtering. Surf. Coat. Technol. 2021, 421, 127430. [CrossRef]

16. Kara, F.; Kurban, M.; Coskun, B. Evaluation of electronic transport and optical response of two-dimensional Fe-doped TiO ${ }_{2}$ thin films for photodetector applications. Optik 2020, 210, 164605. [CrossRef]

17. Lu, J.H.; Chen, B.Y.; Wang, C.H. Investigation of nanostructured transparent conductive films grown by rotational-sequentialsputtering. J. Vac. Sci. Technol. A 2014, 32, 02B107. [CrossRef]

18. Rahimi, N.; Pax, R.A.; Gray, E.M. Review of functional titanium oxides. I: $\mathrm{TiO}_{2}$ and its modifications. Prog. Solid State Chem. 2016, 44, 86-105. [CrossRef] 
19. Santecchia, E.; Hamouda, A.M.S.; Musharavati, F.; Zalnezhad, E.; Cabibbo, M.; Spigarelli, S. Wear resistance investigation of titanium nitride-based coatings. Ceram. Int. 2015, 41, 10349-10379. [CrossRef]

20. Khwansungnoen, P.; Chaiyakun, S.; Rattana, T. Room temperature sputtered titanium oxynitride thin films: The influence of oxygen addition. Thin Solid Films 2020, 711, 138269. [CrossRef]

21. Vaz, F.; Cerqueira, P.; Rebouta, L.; Nascimento, S.M.C.; Alves, E.; Goudeau, P.; Rivière, J.P.; Pischow, K.; de Rijk, J. Structural, optical and mechanical properties of coloured $\mathrm{TiN}_{\mathrm{x}} \mathrm{O}_{\mathrm{y}}$ thin films. Thin Solid Films 2004, 447-448, 449-454. [CrossRef]

22. Barradas, N.; Jeynes, C.; Webb, R.P.; Kreissig, U.; Grötzschel, R. Unambiguous automatic evaluation of multiple Ion Beam Analysis data with Simulated Annealing. Nucl. Instrum. Methods Phys. Res. B 1999, 149, 233-237. [CrossRef]

23. Barradas, N.P.; Pascual-Izarra, C. Double scattering in RBS analysis of PtSi thin films on Si. Nucl. Instrum. Methods Phys. Res. B 2005, 228, 378-382. [CrossRef]

24. Barradas, N.P.; Reis, M. Accurate calculation of pileup effects in PIXE spectra from first principles. X-ray Spectrom. 2006, 35, 232-237. [CrossRef]

25. Angstrom Sciences, Sputtering Yields. Available online: www.angstromsciences.com (accessed on 1 November 2021).

26. Speight, J.G. Lange's Handbook of Chemistry, 16th ed.; McGraw-Hill: New York, NY, USA, 2005; pp. 1-274.

27. Milman, Y.V.; Golubenko, A.A.; Dub, S.N. Indentation size effect in nanohardness. Acta Mater. 2011, 59, 7480-7487. [CrossRef]

28. Zhang, S. (Ed.) Thin Films and Coatings: Toughening and Toughness Characterization; CRC Press Taylor \& Francis Group: Boca Raton, FL, USA, 2015. 